\title{
Prevalence and Nature of Internet Use among Adolescents in Vadodara (Gujarat)
}

\author{
Janki Jhala $^{1 *}$, Renu Sharma ${ }^{2}$
}

\section{ABSTRACT}

Internet has been a very facilitating medium and making lives easier for many of us. Internet is increasingly becoming a channel through which people, and especially adolescents, socialize and be in constant contact with their family, relatives and friends. More than a medium of acquiring knowledge, for adolescents, it has become a medium of expression of their implicit feelings and to know what is happening in their peer group. The current research aims to study the prevalence and nature of Internet use among adolescents. Population for the research included adolescents of Vadodara District in Gujarat. A total of 1657 adolescents were taken as the sample for the study. A survey research was conducted on 1657 adolescents using a self developed questionnaire along with Young's Internet Addiction test. Results indicate that $44.8 \%$ of the participants are Average Users of the Internet, while $14.6 \%$ of the participants belong to the category of above average users of the Internet. The present study also shows that participants use the Internet mainly for social communication and social networking sites are the most commonly used sites on the Internet.

Keywords: Internet, Internet Use, adolescents, Social Networking Sites

Discovered only a few decades ago, the Internet is a system of enormous technical and social complexity. It comprises of a gigantic but almost invisible universe that includes thousands of networks, millions of computers, and billions of users across the world (Greenfield \& Yan, 2006). In the past few years, computers and Internet have lost their elite status and has become a basic necessity for today's society. Many scholars, technologists, and social critics believe that these changes and the Internet, in particular, are transforming economic and social life (Anderson, Bikson, Law, \& Mitchell, 1995); (Attewll \& Rule, 1984); (King \& Kraemer, 1995). People use the Internet for various purposes such as entertainment, education, information retrieval, communication, business, etc.

\footnotetext{
${ }^{1}$ Research Scholar, Dept. of Psychology, The M. S. University of Baroda, Vadodara, Gujarat, India

${ }^{2}$ Associate Professor, Dept. of Psychology, The M. S. University of Baroda, Vadodara, Gujarat, India *Responding Author

Received: February 28, 2017; Revision Received: March 23, 2017; Accepted: March 29, 2017

(C) 2017 Jhala J, Sharma R; licensee IJIP. This is an Open Access Research distributed under the terms of the Creative Commons Attribution License (www.creativecommons.org/licenses/by/2.0), which permits unrestricted use, distribution, and reproduction in any Medium, provided the original work is properly cited.
} 
Due to the availability of information over the Internet and easy access to various studies, researches and findings happening across the globe, the modern day education system encourages the use of Internet for its educational value. Internet access and use among adolescents has therefore grown exponentially over the past decade and hence more research has been done towards understanding the habits of Internet usage amongst adolescents than the adult population. For instance, it is reported that the primary purpose for which the adolescents use the Internet is for social reasons (Gross, 2004), despite various activities including doing schoolwork, playing games, shopping, and downloading music. The Internet provides the unique opportunity and social setting for people to interact and share ideas and opinions with individuals across the globe at the click of a button, therefore enhancing the circle of influence beyond all physical boundaries without actually having to move from the comfort of one's home. While the Internet has become an integral part of our lives today, many studies have shown that there are differences based on age group and gender in terms of uses of Internet and the amount of usage.

Most common uses of the Internet:

1. Information seeking: The most common use of the Internet is to seek or search for any type of information. People use various search engines like the Google and the Yahoo to know about news, weather, current affairs, education policies, government policies, laws, science and technology, law and politics, economy etc.

2. Social networking: The Internet and social networking sites are a component of many adolescents' development and life. There are a vast number of social networking sites available for individuals to choose from with multiple factors influencing the decision to use a particular site. With the extensive resources on the Internet, adolescents can create personal pages, provide personal information, and communicate with other people through numerous websites. One of the most popular social networking sites is Facebook. On sites such as this, users are able to provide personal information, continually update information, and even chat with friends.

3. Communication: People from different parts of the world are able to interact and communicate with the help of the Internet. Thanks to email, instant messages and video calling, people who are far from their loved ones can still talk. Because of blogging and social networking websites and online discussion forums, there are platforms that allow people to express themselves.

4. Entertainment: There is a very close relation of Internet to entertainment. Whether it is watching videos in YouTube, playing live games, watching live sports, TV shows, or downloading movies; Internet proves its domination everywhere.

5. Online games: Children are more interested in using the technology for their free play. Playing online games does not require necessarily having a partner unlike playing with other kind of games and free play games that children play at their homes.

6. Online education: This medium benefits both teachers and students. There are thousands of online courses to choose from, which cater to various fields. Aside from being an abundant portal of information, the Internet provides up to the minute news on a certain 
Prevalence and Nature of Internet Use among Adolescents in Vadodara (Gujarat)

subject being tackled. It also reduces barriers for people with physical impairment, who may have problems getting to the library.

7. Current affairs: The Internet helps people to be up to date regarding the current affairs and news. Any event or incident which has taken place few minutes ago is on the Internet. It gives recent and up to date knowledge about the happenings around the world.

8. Gambling: The Internet is now commonly available in the home and the workplace, making it easier to partake in gambling. With an increase in access to an activity there is an increase in that behaviour. Thus, with more gambling opportunities online comes an increase in gamblers as well as an increase in problem gamblers. As the Internet is more accessible, it is becoming cheaper for people to obtain Internet services.

Research suggests that adolescents use a variety of Internet applications such as instant messaging, bulletin boards, chat rooms, and blogs to connect with their peers (Boneva, Quinn, Kraut, Kiesler, \& Shklovski, 2006; Gross, 2004) and to explore typical adolescent issues such as sexuality, identity, and partner selection (Smahel, Brown, \& Blinka, 2012; Subrahmanyam \& Greenfield, 2008).

\section{Indian Scenario}

According to an article published in The Hindu on $24^{\text {th }}$ august 2013, India is the third largest user of Internet after China and the United States. The article also further reports that a global digital measurement and analytics firm, comScore has said in its report that India has over 74 million Internet users over March 2012. The Telecom Regulatory Authority of India (TRAI) quoted the number of Internet subscribers in India at 164.81 million as of March 31, 2013, with almost 87\% having access to Internet via mobile phones.

Approximately 46 percent of India's offline population are youth-a demographic that is typically an early adopter of technology. Since the International Telecommunications Unions's definition of Internet users includes only the population above 6 years of age, India's future Internet user population could grow rapidly (as of 2012, its median age was the lowest in the world, with 58 percent of the total population under the age of 30) (Gnanasambandam, Madgavkar, Kaka, Manyika, Chui, Bughin, \& Gomes, 2012). This demographic dividend will be a key driver of Internet growth in India. Growth projections for India's online population vary widely, ranging from approximately 150 million to 500 million new users by 2018 (Boston consulting Group).

The increase in the Internet penetration in India has been majorly driven by the rapid expansion in mobile network coverage, shrinking device and data plan prices and increasing utility of the Internet (Gnanasambandam et. al 2012). With the expansion of mobile network coverage, mobile connections in India grew at $21 \%$ in 2013. While 2G coverage was reported to be 90 percent, 3G built out had reached around 75 million mobile connections in 2013 (GSMA, 2014). The average 


\section{Prevalence and Nature of Internet Use among Adolescents in Vadodara (Gujarat)}

retail price for a smart-phone in India decreased to 29 percent in 2013. Due in part of falling mobile prices, the smart-phone user base in India exploded from 5 million units in 2008 to 76 million units in 2013. While the falling prices have made a significant contribution to Internet penetration in India, relatively low data plans has also added to the contribution.

The e-commerce market has experienced the most growth in the past decade; while local retailers such as New India Plaza had an online presence as early as 1999; local online retail saw growth only after Flipkart launched in 2007. With the anticipated entry of foreign players such as Amazon in 2014, e-commerce is set to grow tremendously. The impact could be felt more in urban than rural areas; 50 percent of urban online Indian consumers cited online shopping as a main use of the Internet, a higher rate than that of India's rural population.

\section{Objectives}

1. To study the prevalence of Internet use among adolescents.

2. To study the nature of Internet use in context of ,

a. Time participants spent online

b. Use of Social Networking Sties (SNS)

\section{METHODOLOGY}

\section{Sample}

The following study was aimed to find the prevalence of Internet usage among school going adolescents in the age group of 13-19 years in Vadodara district. The population included adolescents, having Internet access, from English medium schools and Gujarati medium schools affiliated to the Gujarat State Education Board (GSEB). For the sample selection, the Vadodara District Education Office was contacted and a list of all the English and Gujarati medium schools was sought. Of all the English and Gujarati medium schools affiliated to the Gujarat State Education Board (GSEB), seven schools were randomly selected through lottery method from the Vadodara city. Similarly, three schools were randomly selected through lottery method from the nearby towns in Vadodara district, viz., Padra, Dabhoi and Sinor. Out of these 10 schools, all the students of grades 9-12 were taken as the participants for the study. Therefore, a total of 1657 participants were the part of the study. Among them 834 were males and 823 were females. There were total of 517 participants studying in English medium schools and 1140 participants studying in the Gujarati medium schools. Of the total sample, 1204 participants belonged to the urban areas while, 453 participants belonged to the rural areas. Out of the total sample, 548 participants were from grade 9; 497 from grade 10; 319 from grade 11 and 293 from grade 12.

\section{Tools}

1. Internet Addiction Test (IAT), developed by Dr. Kimberly Young (1996) consists of 20 items that measures mild, moderate and severe level of Internet use. IAT is a 20 item questionnaire on which respondents are asked to rate items on a five point Likert scale, 
covering the degree to which their Internet use affects their daily routine, social life, productivity, sleeping patterns and feelings. The minimum score is 20 and the maximum is 100; the higher the score, the greater the problem Internet use causes. Young suggests that a score of 20-39 points in an average user of the Internet who has complete control over his/her usage; a score of 40-69 signifies frequent problems due to Internet usage; and a score of 70-100 means that the Internet usage is causing significant problems.

2. A modified version of the European School Survey Project on Alcohol and Other Drugs (ESPAD) Questionnaire, called eu.net.adb, developed by the Hibell, Guttormsson, Ahlström, Balakireva, Bjarnason, Kokkevi and Kraus (2011) and used in a project funded by the Safer Internet programme of the European Commission, was used for the present study. The questionnaire, eu.net.adb was a part of international study on Internet use among European students from seven different countries. The questionnaire contains total of 77 questions with various sub questions within each question. The questions are mostly related to the use of Internet, for what purpose the Internet is used by the participants.

\section{Procedure}

Vadodara district is divided into 8 blocks/talukas, viz., Dabhoi, Karjan, Padra, Sinor, Savli, Waghodia, Vadodara rural and Vadodara city. Since, there is only one block which has the urban population, i.e., Vadodara city. it was separated by the researcher from the other 7 blocks which included the rural population. Out of these 7 blocks, the researcher randomly selected three blocks viz., Dabhoi, Padra and Sinor. School principals from the 10 selected schools were approached and permission was sought to collect the data on an assigned day.. The questionnaires were given to the all the students of Grades 9-12 who were present on the assigned day for data collection.

\section{RESULTS}

\section{Table 1: Total frequency of Internet Users}

\begin{tabular}{|l|l|l|}
\hline & Frequency & Percent \\
\hline Below Average Users (BAU) & 663 & $\mathbf{4 0}$ \\
\hline Average Users (AU) & 743 & $\mathbf{4 4 . 8}$ \\
\hline Above Average Users (AAU) & 242 & $\mathbf{1 4 . 6}$ \\
\hline Significantly Above Average Users (SAAU) & 9 & $\mathbf{0 . 5}$ \\
\hline Total & $\mathbf{1 6 5 7}$ & $\mathbf{9 9 . 9}$ \\
\hline
\end{tabular}

Table 1 describes the frequency of Internet users among the adolescents. As we see from the table, there are $40 \% \%$ of the participants who are "Below Average Users (BAU)" of the Internet; $44.8 \%$ of them who are "Average Users (AU)" of the Internet, $14.6 \%$ of them are "Above Average Users (AAU)" of the Internet while only $0.5 \%$ of them are "Significantly Above Average Users (SAAU)" of the Internet. 
Prevalence and Nature of Internet Use among Adolescents in Vadodara (Gujarat)

Table 2: Gender difference in the use of Internet.

\begin{tabular}{|l|l|l|l|l|}
\hline & Males & $\mathbf{\%}$ & Females & $\%$ \\
\hline BAU & 242 & $\mathbf{2 9}$ & 421 & $\mathbf{5 1 . 1}$ \\
\hline AU & 429 & $\mathbf{5 1 . 4}$ & 314 & $\mathbf{3 8 . 1}$ \\
\hline AAU & 154 & $\mathbf{1 8 . 4}$ & 88 & $\mathbf{1 0 . 7}$ \\
\hline SAAU & 9 & $\mathbf{1}$ & 0 & $\mathbf{0}$ \\
\hline Total & $\mathbf{8 3 4}$ & $\mathbf{9 9 . 8}$ & $\mathbf{8 2 3}$ & $\mathbf{9 9 . 9}$ \\
\hline
\end{tabular}

Table 2 describes the frequency of Internet usage by male and female participants. Results indicate that there are $51.1 \%$ of females who are BAUs of the Internet use as compared to $29 \%$ of the males. Almost half of the male adolescents are Average Users (51.4\%) as compared to their female counterparts which are $38.1 \%$. Results also show that $18.4 \%$ of males are AAUs, while $10.7 \%$ of females are AAUs. Only $1 \%$ of the male population are significantly above average users of the Internet. This implies that males tend to use the Internet more as compared to their female counterparts. Male participants are almost twice as likely as the female participants to use the Internet.

Table 3: Grade wise difference in the use of Internet.

\begin{tabular}{|l|l|l|l|l|l|l|l|l|}
\hline & $\mathbf{9}^{\text {th }}$ & $\mathbf{\%}$ & $\mathbf{1 0}^{\text {th }}$ & $\mathbf{\%}$ & $\mathbf{1 1}^{\text {th }}$ & $\mathbf{\%}$ & $\mathbf{1 2}^{\text {th }}$ & $\mathbf{\%}$ \\
\hline BAU & 216 & $\mathbf{3 9 . 4}$ & 198 & $\mathbf{3 9 . 8}$ & 138 & $\mathbf{4 3 . 2}$ & 111 & $\mathbf{3 7 . 8}$ \\
\hline AU & 256 & $\mathbf{4 6 . 7}$ & 224 & $\mathbf{4 5}$ & 131 & $\mathbf{4 1}$ & 132 & $\mathbf{4 5}$ \\
\hline AAU & 75 & $\mathbf{1 3 . 6}$ & 71 & $\mathbf{1 4 . 2}$ & 47 & $\mathbf{1 4 . 7}$ & 49 & $\mathbf{1 6 . 7}$ \\
\hline SAAU & 1 & $\mathbf{0 . 2}$ & 4 & $\mathbf{0 . 8}$ & 3 & $\mathbf{0 . 9}$ & 1 & $\mathbf{0 . 3}$ \\
\hline Total & $\mathbf{5 4 8}$ & $\mathbf{9 9 . 9}$ & $\mathbf{4 9 7}$ & $\mathbf{9 9 . 8}$ & $\mathbf{3 1 9}$ & $\mathbf{9 9 . 8}$ & $\mathbf{2 9 3}$ & $\mathbf{9 9 . 8}$ \\
\hline
\end{tabular}

Table 3 describes the frequency of Internet usage by the participants studying in different grades. Results indicate that the highest number of participants belonging to the BAU category is from Grade 11 (43.2\%), followed by Grade 10 and 9 (39.8\% and 39.4\% respectively) and the least being that of Grade 12 (37.8\%). Talking about the "AU" category, highest number of participants belong to Grade 9 (46.7\%), followed by Grade 10 and 12 (45\% each) and the least of them belong to Grade 11 consisting of $41 \%$ of the total sample. Grade 12 participants (16.7\%), reported being the highest users in the "AAU" category, followed by Grade 11 (14.7\%), Grade 10 (14.2\%) and Grade 9 (13.6\%). Approximately 1\% of the Grade 10 and 11 participants reported being SAAUs of the Internet.

Table 4: Medium wise differences in the use of Internet.

\begin{tabular}{|l|l|l|l|l|}
\hline & English Medium & $\mathbf{\%}$ & Gujarati Medium & $\mathbf{\%}$ \\
\hline BAU & 135 & $\mathbf{2 6 . 1}$ & 528 & $\mathbf{4 6 . 3}$ \\
\hline AU & 265 & $\mathbf{5 1 . 2}$ & 478 & $\mathbf{4 1 . 9}$ \\
\hline AAU & 114 & $\mathbf{2 2}$ & 128 & $\mathbf{1 1 . 2}$ \\
\hline SAAU & 3 & $\mathbf{0 . 6}$ & 6 & $\mathbf{0 . 5}$ \\
\hline Total & $\mathbf{5 1 7}$ & $\mathbf{9 9 . 9}$ & $\mathbf{1 1 4 0}$ & $\mathbf{9 9 . 9}$ \\
\hline
\end{tabular}

(C) The International Journal of Indian Psychology, ISSN 2348-5396 (e)| ISSN: 2349-3429 (p) | 33 
Table 4 shows the frequency of Internet usage by English and Gujarati medium participants. Results indicate that there are $26.1 \%$ of English medium participants who are "BAUs" as compared to $46.3 \%$ of the Gujarati medium participants. English medium participants are more of "AUs" and "AAUs" (51.2\% and 22\% respectively) as compared to Gujarati medium participants (41.9\% and $11.2 \%$ respectively).

Table 5: Area wise differences in the use of Internet.

\begin{tabular}{|l|l|l|l|l|}
\hline & Urban & \% & Rural & \% \\
\hline BAU & 458 & $\mathbf{3 8}$ & 205 & $\mathbf{4 5 . 2}$ \\
\hline AU & 549 & $\mathbf{4 5 . 5}$ & 194 & $\mathbf{4 2 . 8}$ \\
\hline AAU & 189 & $\mathbf{1 5 . 7}$ & 53 & $\mathbf{1 1 . 7}$ \\
\hline SAAU & 8 & $\mathbf{0 . 6}$ & 1 & $\mathbf{0 . 2}$ \\
\hline Total & $\mathbf{1 2 0 4}$ & $\mathbf{9 9 . 8}$ & $\mathbf{4 5 3}$ & $\mathbf{9 9 . 9}$ \\
\hline
\end{tabular}

Table 5 describes the use of Internet among participants residing in urban and rural areas of Vadodara city. Results indicate that there are 38\% of urban participants who are "BAUs", as compared to $45.2 \%$ of the rural participants. There are more urban participants who are “Average” and "Above Average Users" (45.5\% and 15.7\%, respectively) as compared to their rural counterparts, which are $42.8 \%$ and $11.7 \%$ respectively. This indicates that higher number of AUs and AAUs belong to the urban areas as compared to the rural areas.

Table 6: Use of Social Networking Sites (SNS)

\begin{tabular}{|l|l|l|}
\hline Social Networking Sites & Total Users & $\mathbf{\%}$ \\
\hline Facebook & 410 & $\mathbf{2 4 . 7}$ \\
\hline Twitter & 648 & $\mathbf{3 9 . 1}$ \\
\hline Orkut & 44 & $\mathbf{2 . 6}$ \\
\hline MySpace & 36 & $\mathbf{2 . 1}$ \\
\hline Others, such as Hike, WeChat, Whats App, etc. & 535 & $\mathbf{3 2 . 2}$ \\
\hline
\end{tabular}

Table 6 shows the results of the total number of participants using a particular social networking site. The results indicate that out of the total of 1657 participants, 410 use Facebook, which is almost a quarter of them (24.7\%) 648 use Twitter (39.1\%), 44 of them use Orkut (2.6\%), 36 use MySpace (2.1\%) and 535 participants (32.2\%) use other social networking and chatting apps such as WeChat, WhatsApp, Hike, etc through their mobile phones. Thus, we observer that Twitter, Facebook and other social networking sites accessed through mobile phones are among the most commonly used social networking sites. 
Prevalence and Nature of Internet Use among Adolescents in Vadodara (Gujarat)

Table 7: Differences in the use of Social Networking Sites (SNS) by different categories of the Internet users.

\begin{tabular}{|l|l|l|l|l|l|l|l|l|l|l|}
\hline & BAU & $\mathbf{\%}$ & AU & $\mathbf{\%}$ & AAU & \% & SAAU & \% & Total & $\%$ \\
\hline Facebook & 64 & $\mathbf{1 5 . 6}$ & 236 & $\mathbf{5 7 . 5}$ & 104 & $\mathbf{2 5 . 3}$ & $\mathbf{6}$ & 1.4 & 410 & $\mathbf{9 9 . 8}$ \\
\hline Twitter & 161 & $\mathbf{2 4 . 8}$ & 343 & $\mathbf{5 2 . 9}$ & 138 & $\mathbf{2 1 . 2}$ & $\mathbf{6}$ & 0.9 & 648 & $\mathbf{9 9 . 8}$ \\
\hline Orkut & 12 & $\mathbf{2 7 . 2}$ & 22 & $\mathbf{5 0}$ & 9 & $\mathbf{2 0 . 4}$ & $\mathbf{1}$ & 2.2 & 44 & $\mathbf{9 9 . 8}$ \\
\hline MySpace & 4 & $\mathbf{1 1 . 1}$ & 14 & $\mathbf{3 8 . 9}$ & 16 & $\mathbf{4 4 . 5}$ & $\mathbf{2}$ & 5.5 & 36 & $\mathbf{1 0 0}$ \\
\hline $\begin{array}{l}\text { Others } \\
\text { (WhatsApp, } \\
\begin{array}{l}\text { WeChat, } \\
\text { etc. }\end{array}\end{array}$ & 152 & $\mathbf{2 8 . 4}$ & 285 & $\mathbf{5 3 . 2}$ & 93 & $\mathbf{1 7 . 3}$ & $\mathbf{5}$ & 0.9 & 535 & $\mathbf{9 9 . 8}$ \\
\hline
\end{tabular}

Table 7 shows the difference among the three categories of Internet users and their use of a particular social networking site. The results depict that out of a total of 410 Facebook users, $15.6 \%$ of them are the BAUs, a little more than half (57.5\%) of them are "AUs, while $25.3 \%$ of them are AAUs. Around $1.4 \%$ of the total users of Facebook are SAAUs. Similarly, for Twitter, we have $52.9 \%$ of the participants who are AUs, while $21.2 \%$ of them are the AAUS and $24.8 \%$ of the BAUs use Twitter. Comparing all the four types of users, we observe that AUs are in majority when it comes to using the social networking sites such as Facebook and Twitter, except that AAUs outnumber them in using MySpace (44.5\%). The results show that more than half (53.2\%) of the total AU participants access other social networking sites like Hike, WeChat, Whats App, etc. On the whole, we observe that among the all users of the Internet, Twitter, Facebook and other social networking sites and apps are more preferred.

Table 8: Gender differences in the use of different SNS

\begin{tabular}{|l|l|l|l|l|l|l|}
\hline & Males & \% & Female & \% & Total & \% \\
\hline Facebook & 272 & $\mathbf{6 6 . 3}$ & 138 & $\mathbf{3 3 .}$ & 410 & $\mathbf{9 9 . 9}$ \\
\hline Twitter & 431 & $\mathbf{6 6 . 5}$ & 217 & $\mathbf{3 3 . 4}$ & 648 & $\mathbf{9 9 . 9}$ \\
\hline Orkut & 25 & $\mathbf{5 6 . 8}$ & 19 & $\mathbf{4 3 . 1}$ & 44 & $\mathbf{9 9 . 9}$ \\
\hline MySpace & 29 & $\mathbf{8 0 . 5}$ & 7 & $\mathbf{1 9 . 5}$ & 36 & $\mathbf{1 0 0}$ \\
\hline Others & 270 & $\mathbf{5 0 . 4}$ & 265 & $\mathbf{4 9 . 5}$ & 535 & $\mathbf{9 9 . 9}$ \\
\hline
\end{tabular}

Table 8 describes the difference in the use of social networking sites by males and females. The results indicate that as many as $66.3 \%$ of the males use Facebook and $66.5 \%$ of them use Twitter, whereas only $33.6 \%$ and $33.4 \%$ of the females use these two SNS respectively. MySpace is also more common among the males and is used by $80.5 \%$ of the male participants as compared to $19.5 \%$ of the female participants. There is not much difference seen in the use of Other SNS by either of the participants. We observe that the males outnumber the females in using all the above mentioned sites that they engage into while socializing. 
Prevalence and Nature of Internet Use among Adolescents in Vadodara (Gujarat)

Table 9: Grade wise differences in the use of different SNS

\begin{tabular}{|l|l|l|l|l|l|l|l|l|l|l|}
\hline & $\mathbf{9}^{\text {th }}$ & $\mathbf{\%}$ & $\mathbf{1 0}^{\text {th }}$ & $\mathbf{\%}$ & $\mathbf{1 1}^{\text {th }}$ & $\mathbf{\%}$ & $\mathbf{1 2}^{\text {th }}$ & $\mathbf{\%}$ & Total & $\mathbf{\%}$ \\
\hline Facebook & 92 & $\mathbf{2 2 . 4}$ & 134 & $\mathbf{3 2 . 7}$ & 93 & $\mathbf{2 2 . 7}$ & 91 & $\mathbf{2 2 . 2}$ & 410 & $\mathbf{1 0 0}$ \\
\hline Twitter & 210 & $\mathbf{3 2 . 4}$ & 184 & $\mathbf{2 8 . 4}$ & 134 & $\mathbf{2 0 . 6}$ & 120 & $\mathbf{1 8 . 5}$ & 648 & $\mathbf{9 9 . 9}$ \\
\hline Orkut & 16 & $\mathbf{3 6 . 4}$ & 17 & $\mathbf{3 8 . 6}$ & 3 & $\mathbf{6 . 8}$ & 8 & $\mathbf{1 8 . 2}$ & 44 & $\mathbf{1 0 0}$ \\
\hline MySpace & 16 & $\mathbf{4 4 . 4}$ & 11 & $\mathbf{3 0 . 5}$ & 4 & $\mathbf{1 1 . 1}$ & 5 & $\mathbf{1 3 . 8}$ & 36 & $\mathbf{9 9 . 8}$ \\
\hline Others & 134 & $\mathbf{2 5 . 1}$ & 186 & $\mathbf{3 4 . 7}$ & 114 & $\mathbf{2 1 . 3}$ & 101 & $\mathbf{1 8 . 8}$ & 535 & $\mathbf{9 9 . 9}$ \\
\hline
\end{tabular}

Table 9 shows the differences in the use of SNS by participants studying in different grades. We observe from the results that $22.4 \%$ of Grade 9 participants, $32.7 \%$ of the Grade 10 participants, $22.7 \%$ of Grade 11 participants and 22.2\% of Grade 12 participants use Facebook. Grade 9 participants are the highest users of Twitter (32.4\%) as compared to Grade 10 (28.4\%), Grade 11 (20.6\%) and Grade 12 (18.5\%) participants. The results also indicate that $44.4 \%$ of the Grade 9 participants are users of MySpace. Other SNS such as WhatsApp, WeChat, etc are used most by Grade 10 participants (34.7\%), followed by Grade 9 (25.1\%), Grade 11 (21.3\%) and Grade 12 (18.8\%). The general trend observed here is that Grades 9 and 10 participants use more of SNS as compared to Grades 11 and 12 participants.

Table 10: Medium wise differences in the use of SNS

\begin{tabular}{|l|l|l|l|l|l|l|}
\hline & English & \% & Gujarati & \% & Total & \% \\
\hline Facebook & 224 & $\mathbf{5 4 . 6}$ & 186 & $\mathbf{4 5 . 4}$ & 410 & $\mathbf{1 0 0}$ \\
\hline Twitter & 215 & $\mathbf{3 3 . 2}$ & 433 & $\mathbf{6 6 . 8}$ & 648 & $\mathbf{1 0 0}$ \\
\hline Orkut & 16 & $\mathbf{3 6 . 4}$ & 28 & $\mathbf{6 3 . 6}$ & 44 & $\mathbf{1 0 0}$ \\
\hline MySpace & 10 & $\mathbf{2 7 . 7}$ & 26 & $\mathbf{7 2 . 2}$ & 36 & $\mathbf{9 9 . 9}$ \\
\hline Others & 272 & $\mathbf{5 0 . 8}$ & 263 & $\mathbf{4 9 . 1}$ & 535 & $\mathbf{9 9 . 9}$ \\
\hline
\end{tabular}

Table 10 shows the differences in the use of SNS by participants studying in English and Gujarati medium schools. Results indicate $54.6 \%$ of English medium participants and $45.4 \%$ of the Gujarati medium participants use Facebook. Twitter is used by $66.8 \%$ of the Gujarati medium participants and $33.2 \%$ of the English medium participants. Around $72.2 \%$ of the Gujarati medium participants use MySpace whereas, only 27.7\% of the English medium participants use MySpace. Not much difference is seen among the English medium and Gujarati medium participants in terms of using other SNS (50.8\% and $49.1 \%$ respectively).

Table 11: Area wise differences in the use of SNS

\begin{tabular}{|l|l|l|l|l|l|l|}
\hline & Urban & $\mathbf{\%}$ & Rural & \% & Total & \% \\
\hline Facebook & 355 & $\mathbf{8 6 . 6}$ & 55 & $\mathbf{1 3 . 4}$ & 410 & $\mathbf{1 0 0}$ \\
\hline Twitter & 510 & $\mathbf{7 8 . 7}$ & 138 & $\mathbf{2 1 . 2}$ & 648 & $\mathbf{9 9 . 9}$ \\
\hline Orkut & 35 & $\mathbf{7 9 . 5}$ & 9 & $\mathbf{2 0 . 5}$ & 44 & $\mathbf{1 0 0}$ \\
\hline MySpace & 25 & $\mathbf{6 9 . 5}$ & 11 & $\mathbf{3 0 . 5}$ & 36 & $\mathbf{1 0 0}$ \\
\hline Others & 449 & $\mathbf{8 3 . 9}$ & 86 & $\mathbf{1 6}$ & 535 & $\mathbf{9 9 . 9}$ \\
\hline
\end{tabular}


Table 11 shows the differences in the use of SNS by participants residing in urban and rural areas. The results indicate that as many as 86.65 of the urban participants and only $13.4 \%$ of the rural participants use Facebook. Second most used sites by the urban participants (83.9\%) are the other SNS, while only $16 \%$ of the rural participants use the other SNS such as WhatsApp, WeChat, etc. The general observation here is that urban participants are frequent users of these social networking sites as compared to their rural counterparts.

Table 12: Comparison among the amount of time spent on SNS during a normal school day and a weekend/holiday by different Internet users.

\begin{tabular}{|c|c|c|c|c|c|c|c|c|c|c|c|c|c|c|c|c|}
\hline & \multicolumn{8}{|c|}{ On a Normal School Day } & \multicolumn{8}{|c|}{ On a Weekend/Holiday } \\
\hline & BAU & $\%$ & $\overline{\mathrm{AU}}$ & $\%$ & $\overline{\text { AAU }}$ & $\%$ & SAAU & $\%$ & BAU & $\%$ & $\mathbf{A U}$ & $\%$ & AAU & $\%$ & SAAU & $\%$ \\
\hline $\begin{array}{l}\text { A Few } \\
\text { Minutes }\end{array}$ & 278 & 41.9 & 184 & 24.7 & 28 & 11.5 & 1 & 11.1 & 189 & 28.5 & 60 & 8.1 & 7 & 2.9 & 0 & $\mathbf{0}$ \\
\hline $\begin{array}{l}\text { Half an } \\
\text { hour }\end{array}$ & 112 & 16.9 & 224 & 30.1 & 47 & 19.4 & 0 & $\mathbf{0}$ & 135 & 20.3 & 139 & 18.7 & 14 & 5.7 & 1 & 11.1 \\
\hline $1-2$ hours & 46 & 6.9 & 118 & 15.8 & 61 & 25.2 & 0 & $\mathbf{0} \mathbf{0}$ & 100 & 15 & 192 & 25.8 & 32 & 13.2 & 0 & $\mathbf{0}$ \\
\hline $2-3$ hours & 5 & 0.7 & 41 & 5.5 & 34 & 14 & 2 & 22.2 & 46 & $\begin{array}{c}7 \\
7\end{array}$ & 98 & 13.2 & 35 & 14.4 & 0 & $\mathbf{0}$ \\
\hline 3-4 hours & 5 & 0.7 & 22 & 2.9 & 16 & 6.6 & 0 & $\mathbf{0}$ & 15 & 2.2 & 51 & 6.8 & 39 & 16.1 & 1 & 11.1 \\
\hline 4 hours & 24 & 3.6 & 41 & 5.5 & 18 & 7.4 & 3 & 33.3 & 2 & 0.3 & 29 & 3.9 & 23 & 9.5 & 0 & $\mathbf{0}$ \\
\hline $\begin{array}{l}\text { More than } \\
4 \text { hours }\end{array}$ & 1 & 0.1 & 6 & 0.8 & 10 & 4.1 & 2 & 22.2 & 19 & 2.8 & 66 & 8.9 & 63 & 26 & 7 & 77.7 \\
\hline $\begin{array}{l}\text { Missing } \\
\text { Responses }\end{array}$ & 192 & 28.9 & 107 & 14.4 & 28 & 11.5 & 1 & 11.1 & 157 & 23.6 & 108 & 14.5 & 29 & 12 & 0 & $\mathbf{0}$ \\
\hline Total & 663 & 99.7 & 743 & 99.7 & 242 & 99.7 & 9 & 99.9 & 663 & 99.7 & 743 & 99.9 & 242 & 99.8 & 9 & 99.9 \\
\hline
\end{tabular}

Table 12 shows the amount of time participants spend on SNS during a normal school day as well on a weekend or on a holiday. The table shows that $41.9 \%$ of the BAUs use the SNS for only few minutes while, $24.7 \%$ of the AUs spend few minutes, and $11.5 \%$ of the AAUs spend few minutes on SNS on a regular school day. The results indicate that participants tend to use SNS more during a holiday or weekend as compared to on a regular school day. $26 \%$ of the AAUs spend more than 4 hours on a holiday/weekend while only $4.1 \%$ of them spend so much time during the normal school day. Only $2.8 \%$ of the BAUs spend more than 4 hours on SNS during the weekend/Holiday. Results also indicate that $77.7 \%$ of the SAAUs use Facebook for more than 4 hours during a weekend/Holiday whereas only $22.2 \%$ of them do so for more than 4 hours during a regular school day.

\section{DISCUSSION}

Based on the Young's Internet Addiction Test (IAT) criteria, the results of the present study show that $40 \%$ of the participants are Below Average Users (BAUs) of the Internet, a little less than half of the participants (44.8\%) are Average Users (AUs) of the Internet, and $14.6 \%$ of the total participants are Above Average Users (AAUs) of the Internet. However, there are 0.5\% of the total participants who are found to be Significantly Above Average Users (SAAUs) of the Internet. These results are in line with a similar kind of study done on 987 students in India (Goel, Subramanyam \& Kamath, 2013), where it was found that, of the total participants, 74.5\% of them were moderate users of the Internet, while $0.7 \%$ of them were found to be Internet 


\section{Prevalence and Nature of Internet Use among Adolescents in Vadodara (Gujarat)}

Addicts. A study on Professional courses students in Central India, reported $7.4 \%$ of their participants had moderate addiction to the Internet, while $0.3 \%$ had severe Internet addiction (Sharma, Sahu, Kasar \& Sharma, 2014). Similarly, Chathoth, Kodavanji, Nayantara and Pai (2013), reported a prevalence of Internet addiction (comprising moderate and severe addiction) as $18.8 \%$ in undergraduate medical students in Mangalore. Nalwa and Anand (2003) investigated the extent of Interne addiction among school children in India. It was found that $18 \%$ of the participants were Internet addicts. Krishnamurthy and Chetlapalli (2015) in their study among college students in Bengaluru found prevalence of mild Internet addiction as $34 \%$ and that of moderate Internet addiction as $8 \%$.

Various researches done abroad have found similar results which support the present study. For example, in a study on Prevalence of Internet use in Iran (Mazhari, 2012), it was found that out of 976 University students, 21\% of them were High users of the Internet. Other previous researches on university students show the prevalence rate of Internet use to be $26.1 \%$ In the United States (Christakis, Moreno, Jelenchick, Myaing \& Zhou, 2011), 10.6\% in China (Wu \& Zhu, 2004), 17.9\% in Taiwan (Chou \& Hsiao, 2000) and 34.7\% in Greece (Frangos, Frangos \& Sotiropoulos, 2011).

India is a fast growing developing nation and the latest technology never hesitates in making its way in to the Indian society. We observe that most of the students now own a cell phone which was a luxury a decade back. With the introduction of new technology from the developed nations, the rise in the prevalence rate of Internet users has also increased in India.

It was hypothesized that there will be significant difference in the Internet use by male and female adolescents. The results of the present study confirmed the hypothesis. It is seen that females are more of a low or average users of the Internet as compared to males who are more of a high users in terms of Internet use. These findings corroborates with previous studies stating that High use of Internet/ Internet addiction is more common in males than in females (Niemz, Griffiths \& Banyard, 2005; Anderson, 2001; Chou \& Hsiao, 2000; Griffiths, 1998).

The Internet and the Social Networking Sites (SNS) have become an integral component of many adolescents' development and life these days. There are a vast number of SNS available for individuals to choose from with multiple factors influencing the decision to use of a particular SNS. In a national survey carried out in the USA in 2009 it was found that $73 \%$ of the teenagers use Social Networking Sites (Lenhart, Purcell, Smith \& Zickuhr, 2010). Similarly, Gibson, Arnott, Moncur, Martin, Forbes \& Bhachu (2010) found that the use of SNS is most common amongst young people, with 95\% of those under the age of 30. The report states that 'visiting SNS' is the second most common activity done several times a day after 'surfing the net'. Almost a quarter of the participants checked their Facebook several times a day according to this report. 
These findings corroborates with the present study where it was found that Facebook, Twitter and other SNS like WhatsApp, Hike, etc, have emerged out as the most commonly used social networking sites among the adolescents. More than half of the Average users access these SNS, while around a quarter of the Above Average users use Facebook daily. Hargittai's (2007) study of 18- and 19-year old students showed that as many as $74 \%$ of the participants reported using at least one social networking site (from the list of six which included: Facebook, MySpace, Xanga, Friendster, Orkut and Bebo) with Facebook being the most frequently used site.

During the past decade, India has witnessed a remarkable advancement in the field of Information and technology (IT), which has led to the emergence of SNS. Social Networking Sites like facebook, Orkut, MySpace, etc are becoming more and more poplar and has becoming a part of daily life for an increasing number of people (Jain, 2013). SNS provide a virtual life to the Indian students. Students who are not comfortable speaking in front of anyone feel free in their virtual world. When they use social networking websites they feel like in heaven but this addiction kills their inner self confidence and imagination for life time (Kavita, 2015).

There have been numerous studies as to why adolescents use social networking sites. For example, Schmitt, Dayanim and Mattias (2008), are of the opinion that children in early adolescence may be spurred to create personal online homepages due to the development of mastery motivation (one's ability to accomplish a goal, such as online content creation), a key developmental challenge for children aged 6-12 years. While adolescents are developing their self identity in this stage of their life, the Internet provides them with this space where in they can discover their identities and experience with them. These adolescents are able to experiment through making personal blogs and homepages, which are mostly public, and are a self representation on the Internet. These websites act as a tool by which adolescents identity can be explored and personal information can be easily shared.

Also, identity exploration may not be the only reason for these adolescent to get hooked on to the SNS. Factors like social communication and social enhancement may as well contribute to the use of SNS. Zywica and Danowski (2008) defined popularity on social networking sites such as Facebook through indicators like number of friends or the amount of wall posts an individual may have. Social networking sites popularity may hold different meanings for people with differing levels of self-esteem and sociability. An analysis of college students' use and perception of popularity on Facebook was used to look at the hypotheses of social enhancement, in which those who have well developed offline social networks have larger online social networks, and social compensation, in which those with less adequate offline social networks compensate for that lack by having more online social networks (Zywica \& Danowski, 2008). Since adolescents at this stage are experimenting intensely with new relationships, they look for comrades or a group of friends where they can feel a sense of belongingness. The Internet, and SNS in particular, serve the dual purpose of anonymity and the need for belongingness. 
It has also been observed from the results of the present study that males use SNS more than the females. Males are twice as likely to use Facebook and Twitter (16.4\% and 26\% respectively) as compared to females (8.3\% and 13\% respectively). Similar findings were also observed by Lenhart (2015), where it was found that boys are more likely than girls to visit Facebook most often (45\% of boys vs. $36 \%$ of girls). Girls are more likely than boys to use Instagram (23\% of girls vs. $17 \%$ of boys) and Tumblr (6\% of girls compared with less than $1 \%$ of boys). Studies have revealed that while females use social networking mainly to maintain and find old relationships, males usually take help of the social media to make new relationships (Mazman \& Usluel, 2011).

The results also indicate that participants of English medium schools are higher users of the SNS as compared to their Gujarati medium counterparts. Also, the present study found that urban users are more as compared to the rural users for various SNS. Probable explanation for this difference may be the fact that there is more awareness of various SNSs among the urban population. Also the availability of new and advanced technology that offers easy access to urban population than to the rural population. With poor mobile networks, and the latest technology taking its time to reach the rural parts, these adolescents are a bit regressed in terms of their usage of Internet as well as SNS.

\section{CONCLUSION}

India is a developing country with embracing technological advancements at a growing pace. Teens today are hooked onto their mobile phones and laptop, doing numerous things on the Internet. The results show that though Internet addiction is in its initial phase in Indian adolescents, as compared to their western counterparts, it won't be a long time that this addiction would increase within a couple of years. Results also show that adolescents use a lot of social networking sites and are deprived of real face to face friendships and relationships. The role of Internet in our lives is beyond doubts and its usage is only going to increase in future. The real challenge for adolescents and their care takers is to have control on the time spent on the Internet and social networking sites. Parents need to explain to their children the pros and cons of the Internet, and to balance their time between Internet surfing, other physical activities and studying.

\section{Acknowledgments}

The author appreciates all those who participated in the study and helped to facilitate the research process.

Conflict of Interests: The author declared no conflict of interests. 


\section{REFERENCES}

Anderson, K. (2001) Internet use among college students: An exploratory study. Journal of American College Health. 50(1):21-26

Anderson, R. H., Bikson, T. K., Law, S. A., \& Mitchell, B. M. (1995). Universal access to email: Feasibility and societal implications.

Attewll, P., \& Rule, J. (1984). Computing and organizations: What we know and what we don't know. Communication of the ACM .

Boneva, S. S., Quinn, A., Kraut, R. E., Kiesler, S., \& Shklovski, I. (2006). Teenage communication in the instant messaging era. In R. E. Kraut, Information Technology at home (pp. 612 - 672). New York: Oxford University Press.

Chathoth, V. M., Kodavanji, B., Nayanatara, A. K. \& Pai, S. R. (2013). Internet behaviour pattern in undergraduate medical students in Mangalore. International Journal of Innovative Research in Science, Engineering and Technology, 2.

Chou, C. \& Hsiao, M. C. (2000). Internet addiction, usage, gratification, and pleasure experience: the Taiwan college students' case. Comput Educ. 35(1):65-80. doi:10.1016/S0360-1315(00)00019-1.

Christakis, D. A., Moreno, M. M., Jelenchick, L., Myaing. M. T. \& Zhou, C. (2011). Problematic Internet usage in US college students: a pilot study. BMC Med. 9:77.

Correspondent, S. (2017). India is now world's third largest Internet user after U.S., China. The Hindu. Retrieved 1 March 2017, from http:/www.thehindu.com/scitech/technology/Internet/india-is-now-worlds-third-largest-Internet-user-after-uschina/article5053115.ece

Frangos, C. C., Frangos, C. C. \& Sotiropoulos, I. (2011). Problematic Internet Use among Greek university students: an ordinal logistic regression with risk factors of negative psychological beliefs, pornographic sites, and online games. Cyberpsychol Behav Soc Netw. 14(1-2):51-8.

Gibson, L., Arnott, J., Moncur, W., Martin, C., Forbes, P., \& Bhachu, A. (2010). Designing social networking sites for older adults. Proceedings of the HCI10 Conference on People and Computers XXIV, Dundee, UK (pp. 186-194).

Gnanasambandam, C., Madgavkar, A., Kaka, N., Manyika, J., Chui, M., Bughin, J. \& Gomes, M. (2012). Online and upcoming: The Internet's impact on India, McKinsey \& Company.

Goel, D., Subramanyam, A. \& Kamath, R. (2013). A Study on the Prevalence of Internet Addiction and its Association with Psychopathology in Indian Adolescents. Indian $J$ Psychiatry. 55: 140-143.

Greenfield, P., \& Yan, Z. (2006). Children, adolescents, and the Internet: A new field of inquiry in developmental psychology. Journal of Applied Developmental Psychology .

Griffiths, M. (1998). Internet addiction: Does it really exist? In J. Gackenbach (Ed.), Psychology and the Internet: Intrapersonal, interpersonal and transpersonal applications (pp. 61-75). New York: Academic Press. 
Prevalence and Nature of Internet Use among Adolescents in Vadodara (Gujarat)

Gross, E. F. (2004). Adolescent Internet use: What we expect, what teens report. Journal of Applied Developmental Psychology.

GSMA Intelligence report (2015). Rural Coverage: Strategies for sustainability- Country case studies. Available from URL: http://www.gsma.com/mobilefordevelopment/wpcontent/uploads/2015/07/Rural_coverage_strategies_for_sustainability.pdf

Hargittai, E. (2007). Whose space? Differences Among Users and Non-users of Social Network Sites. Journal of Computer-Mediated Communication, 13(1), article 14. Retrieved from http://jcmc.indiana.edu/vol13/issue1/hargittai.html

Internet Users. (2017). Internetlivestats. Retrieved 14 March 2017, from http://www.Internetlivestats.com/Internet-users/india/

Jain, P. (2013). Impact of Social Networking Sites on the Youth of India. International Research Journal of Social Sciences, 3(6): 38-47

Kavita (2015). The Influence of Social Media on Indian Students and Teenagers. Internation Journal of Advance Research in Science and Engineering (IJARSE). 4 (1): 487-493.

King, J. L., \& Kraemer, K. L. (1995). Information infrastructure, national policy, and global competitiveness. Information Infrastructure and Policy .

Krishnamurthy, S. \& Chetlapalli, S. K. (2015). Internet Addition: Prevalence and risk factors: A cross sectional study among college students in Bengaluru, the Silicon Valley of India. Indian Journal of Public Health, 59 (2), 115-121.

Lenhart, A. (2015). Teens, Social Media and Techonoglogy Overview. Pew Research Center.

Lenhart, A., Purcell, K., Smith, A., \& Zickuhr, K. (2010). Social Media and Young Adults. Pew Internet \& American Life Research Center.

Mazhari, S. (2012). The Prevalence of Problematic Internet Use and the Related Factors in Medical Students, Kerman, Iran. Addiction \& Health, 4(3-4), 87-94.

Mazman, S.G., Usluel, Y.K. (2010). "Modeling educaitonal usage of Facebook”, Computers \& Education, 55: 444-453.

Nalwa, K., \& Anand, A. P. (2003). Internet addiction in Students: a cause for concern. CyberPsychology and Behvaior , 653-656.

Niemz K, Griffiths M, Banyard P. (2005) Prevalence of pathological Internet use among university students and correlations with self-esteem, the General Health Questionnaire (GHQ), and disinhibition. Cyberpsychol Behav. 8(6):562-570.

Schmitt, K. L., Dayanim, S., \& Matthias, S. (2008). Personal homepage construction as an expression of social development. Developmental Psychology , 496-506.

Sharma, A., Sahu, R., Kasar, P. K \& Sharma, R. (2014). Internet Addiction among professional courses students: A study from Central India. International Journal of Medical Science and Public Health, 3 (9), 1069-1073.

Smahel, D., Brown, B. B., \& Blinka, L. (2012). Associations between Online Friendship and Internet Addiction among Adolescents and Emerging Adults. Developmental Psychology , 48 (2), 381-288. 
Subrahmanyam, K., \& Greenfield, P. M. (2008). Online communication and adolescent relationships. The Future of Children , 18, 119-146.

Wu, H. R., Zhu, K. J. (2004). Path Analysis on Related Factors Causing Internet Addiction Disorder in College students. Chinese Journal of Public Health. 20, 1363-1364.

Zywica, J. \& Danowski, J. (2008). The Faces of Facebookers: Investigating Social Enhancement and Social Compensation Hypotheses; Predicting Facebook ${ }^{\mathrm{TM}}$ and Offline Popularity from Sociability and Self-Esteem, and Mapping the Meanings of Popularity with Semantic Networks. Journal of Computer-Mediated Communication, 14: 1-34. doi:10.1111/j.1083-6101.2008.01429.x

How to cite this article: Jhala J, Sharma R (2017), Prevalence and Nature of Internet Use among Adolescents in Vadodara (Gujarat), International Journal of Indian Psychology, Volume 4, Issue 2, No. 95, ISSN:2348-5396 (e), ISSN:2349-3429 (p), DIP:18.01.164/20170402, ISBN:978-1-365-84231-3 